\title{
Determination of Phytochemical Constituent, Antioxidant Activity, Total Phenol and Total Flavonoid of Extract Ethanol Phyllanthus emblica Fruit
}

\author{
B Halim ${ }^{1,3}$, RA Syahputra ${ }^{2, *}$, I Adenin ${ }^{3}$, HP Lubis ${ }^{3}$, F Mendrofa ${ }^{4}$, S Lie', SE Nugraha ${ }^{6}$
}

\section{B Halim1,3, RA Syahputra ${ }^{2, *}$, I Adenin $^{3}$, HP Lubis ${ }^{3}$, F Mendrofa ${ }^{4}$, S Lie $^{5}$, SE Nugraha ${ }^{6}$}

${ }^{1}$ Faculty of Medicine, Universitas Prima Indonesia, Sumatera Utara, Medan, INDONESIA.

${ }^{2}$ Department of Pharmacology, Faculty of Pharmacy, Universitas Sumatera Utara, Sumatera Utara, Medan, INDONESIA. ${ }^{3}$ Department of Obstetrics and Gynecology, Faculty of Medicine, Universitas Sumatera Utara, Medan, INDONESIA.

${ }^{4}$ Klinik Riyena Orthomedik, Jakarta, INDONESIA.

${ }^{5}$ Akademi Keperawatan Colombia Asia, Sumatera Utara, Medan, INDONESIA. ${ }^{6}$ Department of Pharmaceutical Biology, Faculty of Pharmacy, Universitas Sumatera Utara, Sumatera Utara, Medan, INDONESIA.

\section{Correspondence}

\section{RA Syahputra}

Department of Pharmacology, Faculty of Pharmacy, Universitas Sumatera Utara, Sumatera Utara, Medan, INDONESIA.

E-mail: rony@usu.ac.id

\section{History}

- Submission Date: 07-10-2021;

- Review completed: 03-11-2021;

- Accepted Date: 15-11-2021.

DOI : 10.5530/pj.2022.14.9

Article Available online http://www.phcogj.com/v14/i1

\section{Copyright}

(C) 2022 Phcogj.Com. This is an openaccess article distributed under the terms of the Creative Commons Attribution 4.0 International license.

\begin{abstract}
Introduction: Phyllanthus emblica (PE) is a plant that grows widely in Indonesia, particularly on Sumatra island. In India, it is known as Indian gooseberry and is frequently used in ayurvedic medicine. PE fruit is well-known for its high antioxidant activity and a variety of pharmacological properties. The purpose of this study was to ascertain the phytochemical composition, antioxidant activity, total phenol, and total flavonoid concentrations. Methods: The fruits were harvested in the Indonesian town of Padang Sidimpuan. Up to $700 \mathrm{~g}$ of dry PE fruit powder was dissolved in 96 percent ethanol and macerated for seven days, with periodic steering daily. The solution was then filtered using Whatman paper no 1 , and the filtered result was evaporated under reduced pressure using a rotary evaporator until a crude extract/ethanol extract of PE (EEPE) was obtained, and the phytochemical constituents, antioxidant activity, total phenol, and flavonoid were analysed. Results: The result shows that EEPE contains some flavonoids such as quercetine, betaine, Trigonelline, Myricitrin, Myricetin, Leucine, and Kaempferol. EEPE as an antioxidant of $7.626 \pm 0.41 \mu \mathrm{g} / \mathrm{dL}$. It shows that the antioxidant activity of the ethanol extract of Phyllanthus emblica is strong ethanol extract of Phyllanthus emblica contains Total Flavonoid was $5.816 \pm 2.81$ (mg QE/g extract) and total phenol was $274.590 \pm 13.61$ (mg GAE/g extract). Conclusions: In summary, extract ethanol of Pyllanthus emblica contains flavonoid and have antioxidant activity and high total phenol and flavonoid levels.
\end{abstract}

Key words: Antioxidant, Total flavonoid, Total phenol, Phyllanthus emblica.

\section{INTRODUCTION}

Phyllanthus emblica (PE) is a plant that is regularly found in Indonesia, particularly on Sumatra island, under the name Balakka. In India, this plant is also commonly found and widely utilised in Ayurvedic medicine under the name Indian gooseberry. PE has long been used on a regular basis to promote hair development, relieve constipation, and alleviate fever and pain. Phyllanthus emblica is a member of the Euphorbiaceae family and is found across the subtropics and tropics, including China, India, Malaysia, and Thailand. The Phyllanthus emblica fruit is quite popular due to its high vitamin $\mathrm{C}$ and phenolic content. According to several reports, Phyllanthus emblica fruit possesses antioxidant, immunomodulatory, and anticancer properties, Analgesic, anti-pyretic, antidiabetic, and antimicrobial. ${ }^{1-6}$

All components of Phyllanthus emblica have been extensively employed in a variety of traditional remedies, including Indian Medicine (Ayurveda), Chinese Traditional Medicine, Tibetan Medicine, and Greek Arabic Medicine. Minority populations of southwest China use the root of Phyllanthus emblica to treat Eczema and the fruit to treat jaundice and diarrhoea. Additionally, it is utilised as an astringent and hemostatic in Nepal. ${ }^{78}$ The bark of Phyllanthus emblica has antioxidant activity and radical scavenging due to its polyphenol compounds $s^{9,10}$. In China, the bark of Phyllanthus emblica is utilised for tannin extraction due to its high tannin content (between
21 and 33 percent). Numerous pharmacological investigations have found Phyllanthus emblica but have concentrated on the fruit, with other portions, such as the bark, receiving less attention. PE is an excellent source of metabolite chemicals, which include flavonoids, saponins, tannins, steroids, and glycosides. The flavonoid compounds contained in $\mathrm{PE}$ are kaempferol-3-O $\alpha$-L-(6"-methyl)rhamnopyranoside, kaempferol-3-O- $\alpha-\mathrm{L}-\left(6^{\prime \prime}\right.$-ethyl) rhamnopyranoside, and other compounds, such as Triacontanol, Triacontanoic acid, $\beta$-Amyrin ketone, Betulonic acid, Daucosterol, Lupeol acetate, $\beta$-Amyrin-3-palmitate, Gallic acid, Betulinic acid, Ursolic acid, Oleanolic acid, Quercetin, Rutin, and Bisabolane. Also, PE fruit is rich in vitamin C, luteolin, and corilagin. ${ }^{11-14}$ This study aim to determine the antioxidant activity, total phenol, and total flavonoid of Phyllanthus emblica ethanol extract.

\section{MATERIALS AND METHODS}

\section{Plant collection}

Fruits were obtained from Padang Sidimpuan, North Sumatra, Indonesia (01o 08' 07"- 01o 28' 19" North Latitude and 99o 13' 53"- 99o 21' 31" East Longitude). After washed and dried, the fruits were crushed until obtaining dry fruit powder.

\section{Extract ethanol Phyllanthus emblica prep- aration}

$700 \mathrm{~g}$ of dry PE fruit powder was dissolved in 96 percent ethanol and macerated for seven days, with periodic steering on a daily basis. After filtering 
the solution using Whatman paper no 1, the filtrate was evaporated under reduced pressure in a rotary evaporator till crude extract/ethanol extract of PE (EEPE) was produced. Then, phytochemical screening was undertaken (alkaloids, flavonoids, tannins, saponins, glycosides, steroids/triterpenoids). ${ }^{15}$

\section{Phytochemical constituent analysis by LC-HRMS}

The phytochemical analysis of Phyllanthus emblica ethanol extract was performed using the TSQ Exactive (Thermo) gradient technique (LSIH, Brawijaya University) with mobile phase A (0.1 percent formic acid in water) and phase B. (0.1 percent formic acid in acetonitrile). The $501 \mathrm{~mm} 1.9 \mathrm{~m}$ Hypersil GOLD Q column was analysed for 70 minutes at a flow rate of $40 \mathrm{~L} / \mathrm{min}$. CompoundDiscoverersoftwarewasused in conjunctionwithmzCloudtoanalysethe data. ${ }^{16}$

\section{DPPH scavenging activity}

The DPPH scavenging activity was determined using a slightly modified Blois technique. We dissolved up to $25 \mathrm{mg}$ EEPE in $25 \mathrm{~mL}$ methanol and sonicated for 30 minutes $(400 \mathrm{C}$ ). It was then centrifuged at $1000 \mathrm{rpm}$ for 10 minutes and diluted to get $6.25 \mathrm{~g} / \mathrm{mL}, 12.5 \mathrm{~g} / \mathrm{mL}$, $25 \mathrm{~g} / \mathrm{mL}, 50 \mathrm{~g} / \mathrm{mL}$, and $100 \mathrm{~g} / \mathrm{mL}$ concentrations. Up to $20 \mathrm{mg} \mathrm{DPPH}$ was dissolved in $100 \mathrm{~mL}$ methanol $(200 \mathrm{~g} / \mathrm{mL})$ and sonicated for 30 minutes at $40 \mathrm{0C}$, followed by centrifugation at $100 \mathrm{rpm}$ for 10 minutes and dilution to reach a control concentration of $40 \mathrm{~g} / \mathrm{mL}$. The extract solution was combined with DPPH, vortexed, and left at a temperature of $270 \mathrm{C}$ for 30 minutes. Itwasthenquantifiedat 517 nmusing a spectrophotometers. ${ }^{17}$ The formula is as follows:

DPPH scavenging activity $($ IC50 $)=($ Absorbance Control - Absorbance Sample)/Absorbance

\section{Total flavonoid content (TFC)}

A total of $10.5 \mathrm{mg}$ ethanol extract of PE was diluted in methanol to a volume of $10 \mathrm{ml}$, pipetted $0.5 \mathrm{ml}$ solution, and then added $1.5 \mathrm{ml}$ methanol, $0.1 \mathrm{ml} \mathrm{10 \%}$ aluminum chloride solution, $0.1 \mathrm{ml} 1 \mathrm{M}$ sodium acetate solution, and $2.8 \mathrm{ml}$ pure water. At a wavelength of $436 \mathrm{~nm}$, measurements were taken five times. The concentration of flavonoids was determined using the substitution method in the linear regression equation and expressed as the equivalent milligrams of quercetin in 1 gramme of extract. ${ }^{18}$

\section{Total phenol content (TPC)}

The Sanchez-Rangel method was used to determine the total phenolic content using the Folin-Ciocalteu reagent. In $10 \mathrm{~mL}$ methanol, $10.5 \mathrm{mg}$ of PE extract was dissolved. A total of $0.5 \mathrm{~mL}$ ethanol PE extract was vortexed for approximately 1 minute with $2.3 \mathrm{~mL}$ water and $0.2 \mathrm{~mL}$ Folin-Ciocalteu reagent, then let to stand for 5 minutes before adding $2 \mathrm{~mL} 20 \%$ sodium carbonate and allowing to stand for 70 minutes. The measurement was performed using a spectrophotometer set to $775 \mathrm{~nm}$. Gallic acid was used as a standard. ${ }^{19}$ Total phenol was calculated by multiplying GAE/g extract by five.

\section{RESULTS AND DISCUSSION}

\section{Phytochemical analysis of ethanol extract of PE}

Determine the composition of ethanol extract of PE used LC-HRMS to analyse its phytochemical constituents. Table 1 summarises the findings.

The results showed that extract ethanol of PE contains some flavonoids such as quercetine, betaine, Trigonelline, Myricitrin, Myricetin, Leucine, and Kaempferol.

\section{DPPH scavenging activity}

The antioxidant activity of $\mathrm{PE}$ used vitamin $\mathrm{C}$ as a comparison, the regression equation is $\mathrm{Y}=17.548 \mathrm{X}+2.731$ with an IC50 value of vitamin $\mathrm{C}$ as much as $2.69 \mathrm{mg} / \mathrm{dl}$. The antioxidant value of EEPE can be seen in Table 2 .

The table 2 above shows the ability of EEPE as an antioxidant with an IC50 value of $7.626 \pm 0.41 \mu \mathrm{g} / \mathrm{dL}$. It shows that the antioxidant activity of the ethanol extract of Phyllanthus emblica is strong.

\section{Total flavonoid dan phenol content}

Total flavonoids from EEPE used gallic acid as a comparison. Total flavonoids contained in the extract and total phenols from EEPE used quercetin as a comparison. The regression equation for determining phenol content is $\mathrm{y}=0.00125 \mathrm{X}+0.0252$, while the regression equation for total flavonoids is $y=0.03689 \mathrm{X}+0.0013$. The results of total flavonoids and total phenol can be seen in Table 3.

Table 1: DPPH scavenging activity of PE.

\begin{tabular}{ccccc} 
No. & Name & Formula & Molecular Weight & Retention Time (min) \\
\hline 1. & Quercetine & C15H10O7 & 302.04256 & 117.0792 \\
2. & Betaine & C5H11NO2 & 137.04779 & 0.125 \\
3. & Trigonelline & C7H7NO2 & 283.28737 & 24.585 \\
4. & Stearamide & C18H37NO & 302.00627 & 7.248 \\
5. & Ellagic acid & C14H6O8 & 464.09595 & 7.283 \\
6. & Myricitrin & C21H20O12 & 318.03789 & 7.277 \\
7. & Myricetin & C15H10O8 & 131.09477 & 0.956 \\
8. & Leucine & C5H13NO2 & 286.04784 & 278.22469
\end{tabular}

Table 2: DPPH scavenging activity of PE.

\begin{tabular}{cccc} 
No. & Extract & IC & $(\mu \mathrm{g} / \mathrm{dL}) \pm \mathrm{SD}$ \\
\hline 1. & Ethanol extract of $\mathrm{PE}$ & $7,626 \pm 0.41$
\end{tabular}

Table 3: Total flavonoid and phenol.

\begin{tabular}{|c|c|c|c|}
\hline No. & Extract & $\begin{array}{c}\text { Total Flvonoid } \\
\text { (mg QE/g extract) }\end{array}$ & $\begin{array}{c}\text { Tota Phenol } \\
\text { (mg GAE/g extract) }\end{array}$ \\
\hline 1. & Ethanol extract of PE & $5.816 \pm 2.81$ & $274.590 \pm 13.61$ \\
\hline
\end{tabular}


The table 3 above shows the ability of ethanol extract of Phyllanthus emblicacontains Total Flvonoid was 5.816 \pm 2.81 (mg QE/g extract) and total phenol was $274.590 \pm 13.61$ (mg GAE/g extract).

Phyllanthus emblica (PE) or Indian gooseberry has been widely used as traditional and Ayurvedic medicine in India. PE is commonly spread in Southeast Asia, including Malaysia and Indonesia. A comprehensive toxicity evaluation is needed to ensure the safe use of $\mathrm{PE}^{20-22}$ The active compounds found in PE are apigenin-7-O-(6"-butyryl- $\beta$ glucopyranoside), gallic acid, and luteolin-4'-O-neohesperidoside. ${ }^{23}$ This compound has an antioxidant role; in this study, the scavenging ability of EEPE has an IC50 value of $7.626 \pm 0.41 \mu \mathrm{g} / \mathrm{dL}$ (Table 2). Another study also revealed that luteolin has several cardioprotective mechanisms by means of anti-calcium overload, other luteolin functions can also reduce radical compounds (O-, $\mathrm{H}_{2} \mathrm{O} 2$, and $\left.\mathrm{OH}-\right)$, luteolin also has anticancer activity by stimulating pathway apoptosis. ${ }^{23}$ Moreover, Luteolin has $\mathrm{LD}_{50}$ higher than $5000 \mathrm{mg} / \mathrm{kgBW}$, while Gallic acid has $\mathrm{LD}_{50}$ more than $2000 \mathrm{mg} / \mathrm{kgBW} .^{24,25}$ Research on Antioxidant activity of methanolic extract of Emblica fruit (Phyllanthus emblica L.) from six regions in China, Liu et al.showed that methanol extract of Phyllanthus emblica fruit has strong antioxidant activity derived from phenolic compounds as much as $81.5-120.9 \mathrm{mg}$ gallic acid equivalent (GAE)/g, flavonoid compounds as much as $20.3-3.7 \mathrm{mg}$ quercetin equivalent $(\mathrm{QE}) / \mathrm{g}$ and proanthocyanin compounds as much as $3.7-18.7$ catechin equivalent $(\mathrm{CE}) / \mathrm{g}^{26}$, whereas in this study the total values of flavonoids and total phenols obtained in EEPE are 5,816 $\pm 2.81 \mathrm{mg} \mathrm{QE} / \mathrm{g}$ extract and 274,590 $\pm 13.61 \mathrm{mg} \mathrm{GAE} / \mathrm{g}$ extract, respectively (Table 2).

\section{CONCLUSION}

In summary, extract ethanol of Pyllanthus emblica contains flavonoid and have antioxidant activity and high total phenol and flavonoid levels. For further investigation, Pyhtllanthus emblica extract can be tested into several pharmacological activities by in vitro and in vivo methods.

\section{REFERENCES}

1. Anila L, Vijayalakshmi NR. Antioxidant action of flavonoids from Mangifera indica and Emblica officinalis in hypercholesterolemic rats. Food chemistry. 2013;83(4):569-574.

2. LiuX, Zhao M, Wu K, ChaiX, Yu H, Tao Z, Wang J. Immunomodulatory and anticancer activities of phenolics from emblica fruit (Phyllanthus emblica L.). Food Chemistry. 2003;131(2):685-690.

3. Khopde SM, Priyadarsini KI, Mohan H, Gawandi VB, Satav JG, Yakhmi JV, Mittal JP. Characterizing the antioxidant activity of amla (Phyllanthus emblica) extract. Current science. 2001;185-190.

4. Liu X, Zhao M, Luo W, Yang B, Jiang Y. Identification of volatile components in Phyllanthus emblica $L$. and their antimicrobial activity. Journal of Medicinal food. 2012;12(2):423-428.

5. Perianayagam JB, Sharma SK, Joseph A, Christina AJM. Evaluation of anti-pyretic and analgesic activity of Emblica officinalis Gaertn. Journal of ethnopharmacology. 2004;95(1):83-85.

6. Sharma P, Joshi T, Joshi T, Chandra S, Tamta S. In silico screening of potential antidiabetic phytochemicals from Phyllanthus emblica against therapeutic targets of type 2 diabetes. Journal of ethnopharmacology. 2020;248(1):112268.

7. Gaire BP, Subedi L. Phytochemistry, pharmacology and medicinal properties of Phyllanthus emblica Linn. Chinese journal of integrative medicine. 2014;1(8):24.

8. Mirunalini S, Krishnaveni M. Therapeutic potential of Phyllanthus emblica (amla): the ayurvedic wonder. Journal of basic and clinical physiology and pharmacology. 2010;21(1):93-105.

9. Liu X, Cui C, Zhao M, Wang J, Luo W, Yang B, Jiang Y. Identification of phenolics in the fruit of emblica (Phyllanthus emblica L.) and their antioxidant activities. Food chemistry. 2008;109(4):909-915.
10. Charoenteeraboon J, Ngamkitidechakul C, Soonthornchareonnon N, Jaijoy K, Sireeratawong S. Antioxidant activities of the standardized water extract from fruit of Phyllanthus emblica Linn. Sonklanakarin Journal of Science and Technology. 2010;32(6):599.

11. Poltanov EA, Shikov AN, Dorman HD, Pozharitskaya ON, Makarov VG, Tikhonov VP, Hiltunen R. Chemical and antioxidant evaluation of Indian gooseberry (Emblica officinalis Gaertn, syn. Phyllanthus emblica L.) supplements. Phytotherapy Research. 2009;23(9):13091315

12. Luo W, Zhao M, Yang B, Ren J, Shen G, Rao G. Antioxidant and antiproliferative capacities of phenolics purified from Phyllanthus emblica L. fruit. Food Chemistry. 2011;126(1):277-282.

13. Habib-ur-Rehman, Yasin KA, Choudhary MA, Khaliq N, Attaur-Rahman, Choudhary MI, Malik S. Studies on the chemical constituents of Phyllanthus emblica. Natural Product Research. 2007;21(9):775-781.

14. Pientaweeratch S, Panapisal V, Tansirikongkol A. Antioxidant, anticollagenase and anti-elastase activities of Phyllanthus emblica, Manilkara zapota and silymarin: An in vitro comparative study for anti-aging applications. Pharmaceutical biology. 2016;54(9):18651872.

15. Syahputra RA, Lie S, Theo S, Nugraha SE. Antioxidant, Total Phenol, Total Flavonoid, and LC-MS/MS Analysis of Pometia Pinnata Ethanol Extract. In 2021 IEEE International Conference on Health, Instrumentation \& Measurement, and Natural Sciences (InHeNce). $2021 ; 1-5$.

16. Syahputra RA, Harahap U, Dalimunthe A, Pandapotan M, Satria D. Protective effect of Vernonia amygdalina Delile against doxorubicininduced cardiotoxicity. Heliyon. 2021;7(7):e07434.

17. Adrian A, Syahputra RA, Lie S, Nugraha SE. Amelioration of Cisplatininduced Liver Injury by Extract Ethanol of Pometia pinnata. Open Access Macedonian Journal of Medical Sciences. 2021;9(A):665-8.

18. Syahputra RA, Lie S, Nugraha SE, Situmorang PC. Amelioration of Cisplatin-Induced Kidney Injury by Pometia pinnata. Pharmacognosy Journal. 2021;13(5):25.

19. Nugraha SE, Yuandani ES, Syahputra RA. Investigation of phytochemical constituents and cardioprotective activity of ethanol extract of beetroot (beta vulgaris. I) on doxorubicin induced toxicity in rat. Rasayan Journal of Chemistry. 2020;13(02):973-8.

20. Bhandari PR, Kamdod MA. Emblica officinalis (Amla): A review of potential therapeutic applications. International Journal of Green Pharmacy. 2012;6(4):25.

21. Khan $\mathrm{KH}$. Roles of Emblica officinalis in medicine-A review. Bot Res Int. 2009;2(4):218-228.

22. Yadav SS, Singh MK, Singh PK, Kumar V. Traditional knowledge to clinical trials: A review on therapeutic actions of Emblica officinalis. Biomedicine \& Pharmacotherapy. 2017;93:1292-1302.

23. Zhou DC, Zhang H, Luo ZM, Zhu QX, Zhou CF. Prognostic value of hematological parameters in patients with paraquat poisoning. Scientific reports. 2016;6(1):1-9

24. Mahata S, Pandey A, Shukla S, Tyagi A, Husain SA, Das BC, Bharti AC. Anticancer activity of Phyllanthus emblica Linn.(Indian gooseberry): inhibition of transcription factor AP-1 and HPV gene expression in cervical cancer cells. Nutrition and cancer. 2013;65(1):88-97.

25. Zhao T, Sun Q, Marques M Witcher M. Anticancer properties of Phyllanthus emblica (Indian gooseberry). Oxidative medicine and cellular longevity. 2015;2(3):54-59.

26. Liu X, Cui C, Zhao M, Wang J, Luo W, Yang B, Jiang Y. Identification of phenolics in the fruit of emblica (Phyllanthus emblica L.) and their antioxidant activities. Food chemistry. 2008;109(4):909-915. 


\section{GRAPHICAL ABSTRACT}

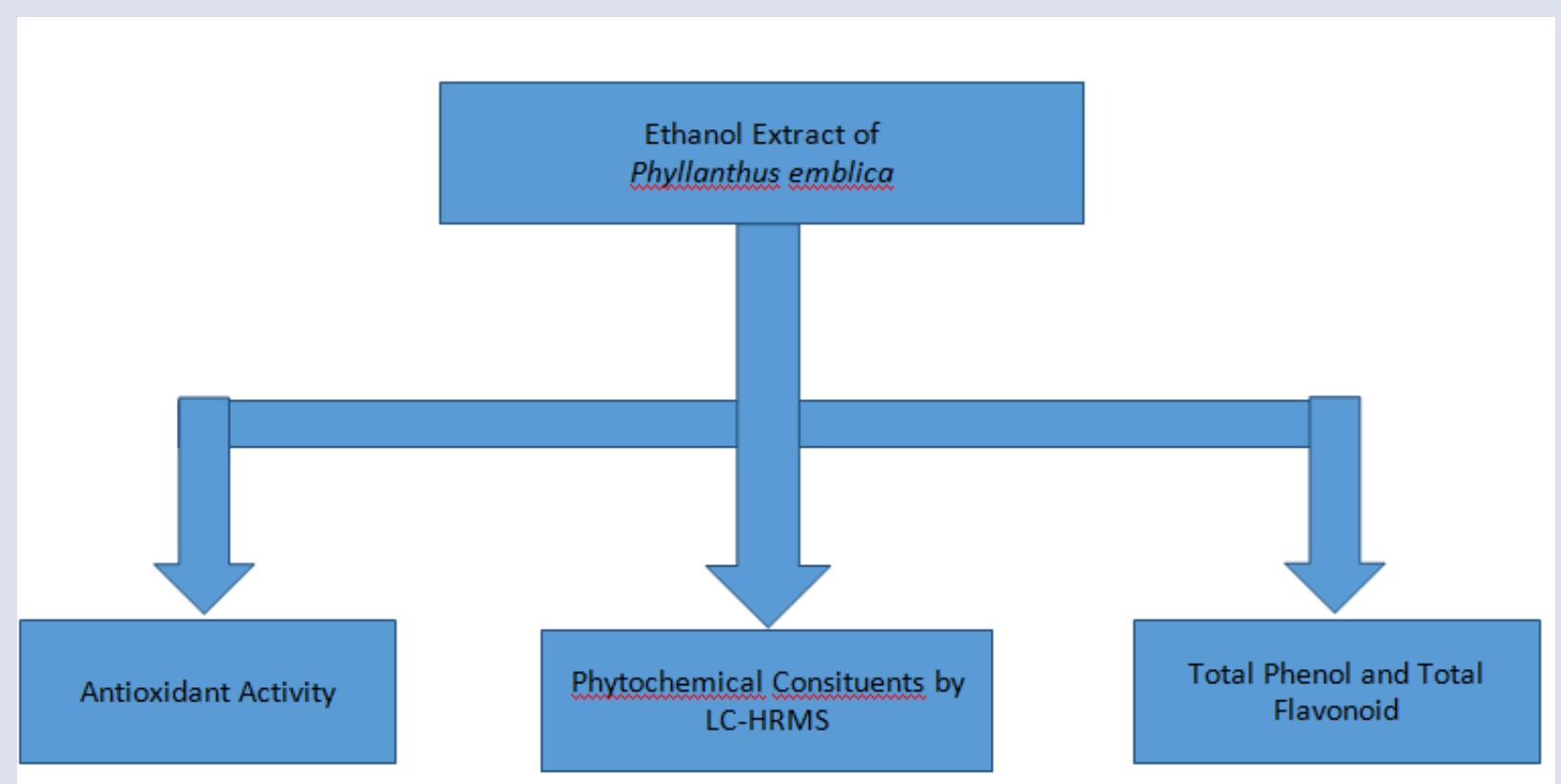

\section{ABOUT AUTHORS}

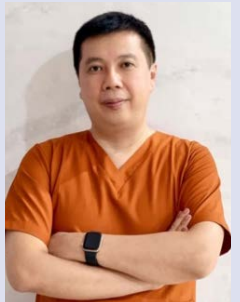

Binarwan Halim, MD, OG(REI), MPH, Ph.D., was born in Medan on February 7, 1966, is a staff and lecturer at the Department of Obstetrics and Gynecology, Faculty of Medicine, Universitas Sumatera Utara. He is the founder and director of Halim Fertility Center (HFC) IVF center in Medan, North Sumatera, Indonesia. He has published many scientific publications related to obstetrics and gynecology in national and international journal articles. His main research interests include infertility, assisted reproduction, early pregnancy loss, endometriosis, and reproductive genetics.

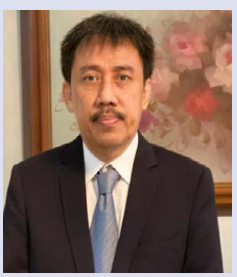

Ichwanul Adenin, MD, OG(REI), Ph.D., was born in Medan on February 23, 1959is a staff and lecturer at the Department of Obstetrics and Gynecology, Faculty of Medicine, Universitas Sumatera Utara. He has published some scientific publications related to obstetrics and gynecology in national and international journal articles. His main research interests include infertility, assisted reproduction, and contraception.

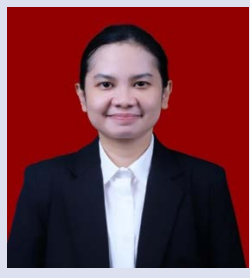

Hilma Putri Lubis, MD, OG(REI)was born in Medan on October 24, 1986, is a gynecologist and an IVF clinician in Halim Fertility Center, which is the third center with the most number of IVF cycles in Indonesia. She is also a lecturer affiliated with the Department of Obstetrics \& Gynecology, Faculty of Medicine, Universitas Sumatera Utara. She has authored and co-authored multiple peer-reviewed scientific papers and presented works at many national and international conferences. Her research interests include PCOS, infertility, Assisted Reproductive Technology (ART) and reproductive genetics.

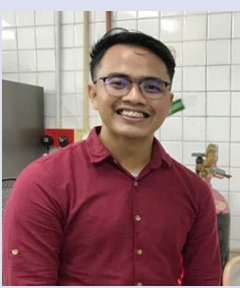

Rony Abdi Syahputra, M.Farm is an active biology lecture in Department of Pharmacology, Faculty Pharmacy, Universitas Sumatera Utara, His also active in pharmacology research especially in toxicology and cardiovascular research. his active as journal reviewer and writing paper in international journal 


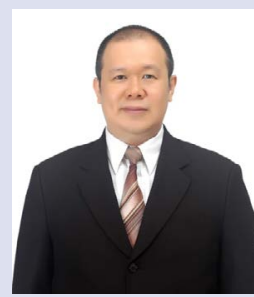

Dr. Sukirman Lie, M. Biomed is active lecture in Akademi Keperawatan Colombia Asia Medan. His also as an active medical aesthetic and active pharmacology research.

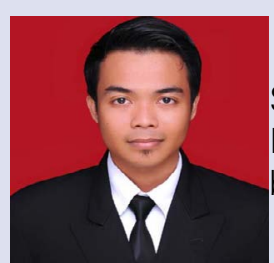

Sony Eka Nugraha, S.Farm., M.Si., Apt is an active biology lecture in Department of Pharmaceutical Biology, Faculty Pharmacy, Universitas Sumatera Utara, His also active in pharmacology and biological research. his active as journal reviewer and writing paper in international journal

Dr. Focoriyena Mendrofa AIFO is an active aesthetic doctor and also active in several pharmacology research.

Cite this article: B, Syahputra RA, Adenin I, Lubis HP, Mendrofa F, Lie S, et al. Determination of Phytochemical Constituent, Antioxidant Activity, Total Phenol and Total Flavonoid of Extract Ethanol Phyllanthus emblica Fruit. Pharmacogn J. 2022;14(1): 63-67. 